Scott Hamilton, U.S. Military Academy

Leslie Brunell, Stevens Institute of Technology

Gunnar Tamm, U.S. Military Academy

Ozer Arnas, U.S. Military Academy 


\title{
Peer Review in Engineering Courses as a Learning Tool
}

\begin{abstract}
Engineering students will often submit assignments that have not been checked for accuracy or whether the results make sense, and rarely are there high marks for presentation. While this is completely unacceptable and unethical in professional engineering, this disturbing trend has become more common (and even acceptable) in the classroom. Many students are defining success as the act of submission of an assignment, while showing little concern for its content or presentation. A learning tool is proposed with the immediate goal of meeting higher standards in student assignments, while lasting goals are to foster a greater sense of ownership and pride in any work that is submitted.
\end{abstract}

This paper presents the results of three independent research projects to explore the use of the professional practice of peer review in engineering courses. This methodology was originally instituted as a system of mandatory collaboration in two structural analysis courses offered at the United States Military Academy (USMA), through forced peer review of all individual homework. Based on the assessments from both students and faculty, various iterations of the peer review concept have emerged in subsequent semesters in both courses, the goals of which remain to increase student learning:

- by interacting with ones classmates

- by having to explain ones own work

- by correcting mistakes and errors in others' work

- by learning ones own abilities and limitations

- by preparing work to be reviewed by others (increased responsibility)

- by modeling the professional aspects of having work reviewed for correctness

In addition to the structural analysis courses, this general methodology was used in a heat transfer course at USMA in which progress reports were peer reviewed during a semester long design project. A third independent application was developed at Stevens Institute of Technology for a fluid mechanics course.

The methods and outcomes of the three studies are assessed and compared in this paper. Student attitudes toward the process and their perceived value of peer review as a learning tool are also examined, based on anonymous survey results. It was found that although apprehensive at first, students eventually took to the idea and its purpose. Surprisingly, data also indicated that peer review grades provided by students matched well with grades provided by the instructors, evidencing that the students took the review process seriously and understood the review criteria. Finally, this paper discusses future work on this project to validate the value of peer review as a learning tool, and offers suggestions for future implementations of this strategy. 


\section{Introduction}

Engineers are charged with designing systems that must serve the public. These systems must be designed, sometimes without prototype, to first and foremost maintain the public's safety, i.e. not to fail. Getting it right is critical! This is a fact that has been recognized since the earliest written laws: Hammurabi's code stated as early as 1780 BCE in law 299,

"If a builder build a house for someone, and does not construct it properly, and the house which he built fall in and kill its owner, then that builder shall be put to death" [1].

There are several other laws (230 through 233), that deal in a similar vein with building failure and offer similar dire consequences in an effort to stress the importance of getting it right. Today while we do not threaten engineers or their family members with death as Hammurabi did, we still do hold the profession to high standards and expect all engineers' work to be correct. Work that firms produce is checked in-house and certified by responsible licensed engineers, signifying that it has been reviewed and is safe and able to perform its intended objective, before it leaves the firm. It follows that our engineering students need to be trained and initiated in this standard if we expect them to adhere to it as practicing members of the profession upon graduation.

"University courses are the preparatory stage to a profession and should therefore encourage learning that reflects the way in which professionals continue to learn and work. "[2]

It was observed that students do not exercise the level of care with their assignments that should be required of young engineers. Not to suggest that the consequences of submitting an incorrect academic assignment are dire, but it seems reasonable that an elevated level of effort should be put forth, especially from students near the end of their undergraduate studies as juniors and seniors. Students often regard their homework submissions as simply a product to be handed in, and the accuracy of their solutions is of minimal concern. This is an unacceptable standard in educating future engineers whose work will be checked by colleagues and non-engineering professionals. Homework assignments are typically checked by the instructor who has a thorough understanding of the concepts. Making students responsible to a peer review replicates the reality they will face as Professional Engineers where their work must be accurate and thoroughly documented. The additional check by a peer should serve as a motivation to complete assignments in an accurate and professional manner. Students should be more responsible for their own learning as well. If they are to truly learn the material, they must take more ownership of it and see it as more than a requirement to be met and endured. Engineering faculty members who implement peer review will introduce their students to a concept not found within a text book yet essential to their future development.

As expressed in the Master Teacher Program at the U.S. Military Academy, one way to develop a students' metacognition, thus their ability for life-long learning, is to view them and treat them as novices in the profession. ${ }^{[3]}$ There is also a large body of research that indicates that students can achieve more when they are working and learning cooperatively. ${ }^{[4-13]}$ The concept of peer review shows that cooperative learning is not limited to completing work but extends to checking 
that work as well. Utilizing cooperative learning techniques to check the work of ones peers is a tool all engineering students should be exposed to while undergraduates.

"Weak students working individually are likely to give up when they get stuck; working cooperatively, they keep going. Strong students faced with the task of explaining and clarifying material to weaker students often find gaps in their own understanding and fill them in. Students working alone may tend to delay completing assignments or skip them altogether, but when they know that others are counting on them, they are often driven to do the work in a timely manner. "[14]

Other research shows that students learn better in small structured groups when completing assigned readings and problem sets. ${ }^{[15,16]}$ This clearly was not happening on any level as work was being turned in that obviously was not being checked for even basic errors.

The challenge was to develop a methodology to motivate the students, at a minimum, check their work prior to turning it in and motivate students to prepare and submit a quality assignment since their work would be reviewed by a third party, a member of their class, and not just the professor. This additional check replicates the workplace environment where all work is reviewed by a colleague. A larger goal is improved learning and increased metacognition. Three independent efforts were undertaken by the authors at two institutions to realize similar goals, and answer the question, "Could a peer review methodology, similar to that used in professional practice, be used with student work to improve student learning and the quality of submissions?" In the fall semester of 2005, peer review was initiated in a Fluid Mechanics course at Stevens Institute of Technology and a Heat Transfer course at the United States Military Academy (West Point). These attempts are assessed and compared to methods used in two Structural Analysis courses at the U.S. Military Academy that have been performed and improved over 4 semesters since the spring of 2004.

\section{Structural Analysis Courses at the U.S. Military Academy}

Like all engineering design, developing a system to improve students' learning and motivate them to check their work was an iterative process. At the U.S. Military Academy, the peer review process was initially implemented during 4 semesters of two related civil engineering courses ( 2 semesters of Structural Analysis, 2 semesters of Advanced Structural Analysis). The evolution of the process and significant findings are presented below, based on a more detail description of the initial results of 2 semesters. ${ }^{[1]]}$ Each iteration produced results that led to revisions and modifications, each evolving towards a "final design" of the peer review methodology in an attempt to address the hypothesis that peer review can promote learning and improve student submissions.

Spring 2004 - Structural Analysis

During the spring of 2004, a system of mandatory collaboration was instituted in a Structural Analysis course, through forced peer review of all individual work. Part of the reason for instituting this was to take advantage of the "positive benefits associated with frequent student 
interaction." ${ }^{[18]}$ This required junior level course included 41 civil engineering majors. The goals were to increase student learning by:

- having students learn from their classmates

- having to explain their own work to others

- correcting mistakes and errors in others' work

- recognizing their own abilities and limitations

- modeling the professional aspects of having work reviewed for correctness

It was speculated that as the students identified errors they would gain skills in error tracking: finding the source of errors and becoming more independent to check their own work. As all grading is performed by the instructors at West Point (no teaching assistants), a collateral benefit of this process would be simpler grading of presumably more accurate student submissions, or so it was hoped!

The peer review requirement was introduced in the course administrative letter, which stated:

In order to insure correctness, this semester I will often require you to consult with your classmates, or myself, and have them sign off on submissions to signify they are in agreement with your work. The goal is to have you check your work and learn from your classmates (peer review) as well learning from having to explain what you did. This is probably something new for most of you, but is a valuable part of your learning. It is critical that you show all of your work and leave "foot prints" so that it can be easily followed.

Logistically, there was a place allocated on each homework assignment sheet to have other students initial that they checked over the solutions. This first attempt at peer review included only a few simple instructions, with the assumption that the students would clearly understand and positively respond to the process, given perhaps some initial hostility.

However, this idealistic view did not correlate to the reality observed. While some students did fulfill all expectations, many more did not. In certain instances, students exchanged signatures at the last minute and in plain sight of the teacher, exclaiming "Sign this and I'll sign yours." This was done with no effort to correct, or even look at, the work in question. Some students certified clearly incorrect work as being correct, even though they themselves submitted correct solutions. Others certified work that they themselves had not completed, making an accurate check nearly impossible to make. For many, the process became a meaningless administrative requirement to turning in homework.

However, a positive trend emerged as the semester progressed, with a significant number of students citing the help of their classmates in correcting their work. At West Point, all assistance received on any submitted work must be documented and acknowledged in order to conform to the strict tenets of the Honor Code. Violations usually lead to expulsion from the Academy. The increased learning from peers as documented by students was a significant achievement. It has long been recognized that "a pervasive pattern of positive benefits [is] associated with frequent 
student interaction." [18] While the process was not a total success, it was encouraging that some of the students were indeed benefiting from the peer review system.

As in many universities, the students complete feedback surveys at the end of the semester. This web-based system has questions that are shared across the Academy, some that are common for each department and some that are specific to the course. In the course level assessment criteria given in Table 1, the students were asked directly about peer review. The students' perception of peer review was only marginally positive.

\begin{tabular}{|l|c|c|c|}
\hline Statement & Agreed & Neutral & Disagreed \\
\hline Peer Review helped in turning in better homework & $53 \%$ & $25 \%$ & $22 \%$ \\
\hline Peer Review helped learn more in the course & $36 \%$ & $38 \%$ & $28 \%$ \\
\hline Peer Review is a valuable learning tool & $40 \%$ & $40 \%$ & $20 \%$ \\
\hline
\end{tabular}

Table 1 Student Survey Results, Peer Review Assessment (USMA, Spring 2004, Structural Analysis)

Two of the Academy-level assessment criteria given in Table 2 gauge independent learning and learning from peers. These statements are rated on an agreement scale, with students strongly agreeing (5), agreeing (4), being neutral (3), disagreeing (2) or strongly disagreeing (1). The Spring 2004 Column of Table 2 shows a slight increase was seen from previous semesters' averages for both criteria, although the significance of the gain cannot be proven to be a direct result of the peer review requirements.

\begin{tabular}{|l|c|c|c|c|c|c|}
\hline \multirow{2}{*}{ Statement } & \multicolumn{2}{|c|}{$\begin{array}{c}\text { Average of prior } \\
\text { Semesters with } \\
\text { No review }\end{array}$} & \multicolumn{2}{|c|}{$\begin{array}{c}\text { Score with } \\
\text { Review 2004 }\end{array}$} & \multicolumn{2}{c|}{$\begin{array}{c}\text { Score with } \\
\text { Review } 2005\end{array}$} \\
\cline { 2 - 7 } & Spring & Fall ** & Spring & Fall** & Spring & Fall** \\
\hline $\begin{array}{l}\text { This instructor encouraged students } \\
\text { to be responsible for their own } \\
\text { learning. }\end{array}$ & 4.61 & 4.68 & 4.68 & 4.94 & 4.68 & 4.74 \\
\hline $\begin{array}{l}\text { My fellow students contributed to my } \\
\text { learning in this course }\end{array}$ & 4.37 & 4.34 & 4.53 & 4.55 & 4.64 & 4.67 \\
\hline
\end{tabular}

Table 2 Student Survey Results, General Assessment (USMA, Spring, Structural Analysis, and **Fall, Advanced Structural Analysis)

Fall 2004 - Advanced Structural Analysis

The peer review system was revised and implemented in an Advanced Structural Analysis course in the fall of 2004, which included 18 senior civil engineering students who had previously taken Structural Analysis in the spring. Much more guidance was provided in this iteration early in the semester. Several specifics of what not to do were listed along with penalties to be incurred. The increase in detail was a reaction to the problems from the previous semester, with the core goal to eliminate the signing off on a review that was not actually completed. An inadvertent result was a policy statement that was overly negative and punitive in tone.

Still, not everyone bought into the new approach. In some cases, students would take the 5\% cut for not having the peer review done at all. There were also instances of students including notes that their work did not match their reviewer's work, but they could not find the error. Often 
these comments stemmed from a peer review done shortly prior to the deadline, allowing no time to reflect on the review or to correct mistakes.

However, there were positive results as well. During the first assignment, several students whose work was correct were penalized for signing off on others' work that was not. Apparently the word got out, as subsequent submissions did not see this trend from the previous semester continue. Instead, students would more precisely note the problems with the work under review or they would indicate that it was not complete at the time of the review. There was also much more documentation of help received during the review process, and some students indicated appreciation for the incentive to check their work for accuracy.

Feedback surveys at the end of the semester included course-specific questions regarding the peer review process, including:

1. How did PEER REVIEW help you in learning the material?

2. Do you have any suggestions for me to make PEER REVIEW more valuable for cadets in the future?

3. Will you use PEER review for future assignments, even when not required?

The results in Table 3 reflect a greatly improved acceptance of peer review. The Fall 2004 rows reflect the results of this second iteration. Regarding the first question, the $28 \%$ of responses that are shown as neutral were deemed so because they indicated that the mechanics of the process limited success, largely due to peers not being able to provide a timely review. An acceptance of the process as being helpful in their studies and profession was demonstrated by the majority indicating they would use peer review even when not required. A typical comment in support of peer review was given as:

"Peer review was definitely key in helping me learn the course material on the problem sets-- when I didn't know how to apply something I learned in class, my peers were usually able to help me figure out what I was doing wrong, and how to correct it, which helped me learn more about the subject overall."

Suggestions to improve peer review dealt largely with allowing more time for review. Only one response suggested eliminating peer review.

\begin{tabular}{|l|c|c|c|c|}
\hline \multirow{2}{*}{ Question } & Semester & $\begin{array}{c}\text { Positive } \\
\text { Response }\end{array}$ & Neutral & $\begin{array}{c}\text { Negative } \\
\text { Response }\end{array}$ \\
\hline \multirow{2}{*}{$\begin{array}{l}\text { How did PEER REVIEW help you in } \\
\text { learning the material? }\end{array}$} & Fall 2004 & $56 \%$ & $28 \%$ & $16 \%$ \\
\cline { 2 - 4 } & Spring 2005 & $70 \%$ & $10 \%$ & $20 \%$ \\
\cline { 2 - 4 } & Fall 2005 & $57 \%$ & $13 \%$ & $30 \%$ \\
\hline \multirow{2}{*}{$\begin{array}{l}\text { Will you use PEER review for future } \\
\text { assignments, even when not required? }\end{array}$} & Fall 2004 & $61 \%$ & $22 \%$ & $17 \%$ \\
\cline { 2 - 5 } & Spring 2005 & $81 \%$ & $5 \%$ & $14 \%$ \\
\cline { 2 - 5 } & Fall 2005 & $76 \%$ & $16 \%$ & $8 \%$ \\
\hline
\end{tabular}

Table 3 Survey Results, Peer Review Questions (USMA, Fall 2004/2005, Advanced Structural Analysis, and Spring 2005, Structural Analysis) 
Table 2 indicates a positive trend in both Academy-wide assessment criteria regarding learning from the previous semester, with results higher than seen in the previous 7 years of data (Column Fall 2004). Although the sample was small, only 18 students, the trends were positive and clearly most students liked or recognized the value of peer review. The following comment captures the reluctant acceptance of the peer review process for some students:

\section{"It helped a lot, but that doesn't mean I have to like it."}

While hoping to see an improvement in the final exam average from a very similar exam used in previous years, none was observed. However, overall course grades were higher, largely due to better grades on reviewed and corrected homework submissions.

Spring 2005 - Structural Analysis

The evolution of the peer review process over the initial two semesters was promising, but far from complete. Many reviews were still conducted at the last minute, and assignments were not always corrected, to the tune of, "My work is wrong, but I can't find the error." The challenge continued to be two-fold, in both motivating and persuading students to see the value of the process as an academic learning tool and professional necessity, and creating an effective and well received structure for the process. This involved providing enough time to review the assigned work of others, as well as absorb reviewer feedback and correct one's work as necessary.

In a blinding flash of the obvious, the policy itself was submitted to peer review, prior to use in the Structural Analysis course offered in the spring of 2005. It seemed logical that the policy could benefit from a review by others. Feedback from reviewers suggested five changes.

1. The name "peer review" is not the best choice, as it conjures negative memories of a similarly named process used extensively in a freshman humanities course which, according to the students, was poorly executed and ill received. ${ }^{[19]}$

2. The tone of the peer review policy letter should be less punitive in nature.

3. Professional practice should be emphasized as the main reason for the process.

4. There should be more time to review work prior to the submission deadline.

5. A more formal process of recording reviews should be employed, and more reminders of exactly what the review should accomplish.

In the spring of 2005, a new group of 50 students were enrolled who had not yet experienced peer review in previous engineering courses. Taking into account the comments provided by reviews and past students' comments a new policy that addressed these concerns was developed (See Appendix A).

In addition the methodology for the review process was explained more diligently, since the students had not yet experienced peer review in other engineering courses. The policy was introduced early in the semester, combining it with a discussion on professional responsibility and ethics. This took about two-thirds of a lesson and included examples and details of what was to be done and why. The material value of peer review was discussed with an example of how 
the engineering firm of the co-teacher's brother concluded that peer review actually saves the firm money. During the first two submissions, the reviews were assessed by the teacher and copies were returned to the reviewers with comments. The detail in subsequent student reviews hence improved. Students who did a particularly good job were publicly recognized throughout the semester, noting the specifics of what made it a particularly stellar review.

After a few assignments, the students suggested a modification to the review deadlines to better fit into their schedules and to allow more time to formulate sound reviews. To the great pleasure of the students their feedback was immediately implemented, no doubt leading to greater acceptance of the process. This complete training in as well as "marketing" of, or persuading and providing proper motivation for the students to accept, the methodology was instrumental to its acceptance and success, something that was previously missing.

The feedback survey results shown in Table 2 indicates that this iteration shown in the Spring of 2005 column was more effective than previous attempts in the same Structural Analysis course, both with and without peer review. Table 3 (Spring 2005 rows) confirms that students placed a greater responsibility for their learning upon both themselves and their peers. Specific comments from students can be found in Appendix C:

\section{Fall 2005 - Advanced Structural Analysis}

This system was used again in the fall of 2005 in Advanced Structural Analysis with 41 students who had all used this methodology during the previous semester. The results in Tables 2 (Fall 2005 column) and 3 (Fall 2005 rows) show a slight downward trend in the students' perception of peer review, although their reliance on other students for contributing to their learning continued to increase. Obviously this was not the anticipated result, as the same students had welcomed the process previously under the same guidelines. The assumption that the students had already bought into the system might have been premature, and so a continual strong emphasis on the value of the process should have been maintained. The extra work performed by the students should also have been recognized more frequently, as there were more who found the requirement to be a burden and had considerable frustrations with time requirements to complete the process.

However, it is important to note that the overwhelming majority of students still said they would continue to use peer review, or some version of it, even if not required. Representative student comments can be found in Appendix D:

One positive trend has been noted on the final exam averages. In both courses the final exam results showed a positive trend in 2005, the semesters when the peer review methodology was used in a "final" form. Table 4 below shows the final exam results for both courses. 


\begin{tabular}{|l|c|c|}
\hline Course & $\begin{array}{c}\text { Final Exam Score with } \\
\text { Review, 2004 } \\
\text { (early form) }\end{array}$ & $\begin{array}{c}\text { Final Exam Score with } \\
\text { Review, 2005 } \\
\text { (final form) }\end{array}$ \\
\hline Structural Analysis (Spring) & $82.3 \%$ & $89.1 \%$ \\
\hline Advanced Structural Analysis( Fall) & $83.9 \%$ & $86.6 \%$ \\
\hline
\end{tabular}

Table 4 Final Exam grades (USMA, Spring, Structural Analysis, and Fall, Advanced Structural Analysis)

\section{Heat Transfer Course at the U.S. Military Academy}

The peer review process was utilized in a senior level Heat Transfer course (ME480) during the fall of 2005 in conjunction with a semester long design project. 42 cadets were enrolled in the course. The design project included two interim progress reports (IPRs) and a final report, of which the two IPRs were peer reviewed.

IPR \#1

The importance of peer review as outlined in the above sections was emphasized to the students. Certain aspects of professional journal review were retained, such as the reviewer being aware of the author's name but not vice versa. This approach was taken to allow for candid reviews. Secondly, as reviewers recommend the fate of a journal manuscript to an editor, the student reviewer included a suggested grade which counted towards $25 \%$ of the total IPR grade $(75 \%$ from instructor). This placed more responsibility on the reviewer to put effort into the review.

The first IPR of the design project was intended to lead to the same results, although each student provided a separate submission in the standard format. Only after the IPR was submitted, were the students told about the peer review process. The IPRs were assigned to student reviewers (one per cadet), 2 days allowed for the review, and another 4 days for authors to make changes based on the feedback from the reviews. To the delight of many, this meant a second chance to turn in a good final product for the teacher to grade! Wording in the review instruction included:

Peer-review is a critical part of validating the integrity of scientific research and maintaining a high quality of its presentation. Exactly the same standards should apply to your work as cadets and future leaders in your profession.

A detailed "cut sheet" was provided, to maintain some uniformity in the grades. It was also made clear that the grades provided by reviewers would be considered in the total IPR grade.

Space was allocated for comments for both content and presentation on the back of the review sheet. As expected, not everyone jumped on the opportunity to provide comments, an indication of a hasty review. This was addressed in the review process of the second IPR.

In comparing student and instructor grades for IPR \#1, it should be noted that the student reviewed the original draft while the instructor reviewed the final draft. Thus, a quantitative comparison of the student reviewer and instructor grades would not be based on the same work. 
But a trend that was observed was that the higher scoring IPRs had a smaller deviation between the two grades. Possible reasons could be that the higher scoring IPRs were already of quality work as first drafts, graded by the students. Other reasons could be that the lower scoring IPRs are more difficult to grade in general, and more prone to subjective grading. These trends were expressed to the class to acknowledge the reviewer efforts and to recognize the similarities in both sets of grades.

\section{IPR \#2}

The second IPR was completed in groups of 3-4 students, and included a greater element of design. Hence, each IPR applied similar principles but did not reveal the same solutions. Each IPR was reviewed by an equivalent number of student reviewers as there were authors (3-4). The same IPR was also reviewed by the instructor for a total of 4-5 reviews for each IPR. The criteria included greater scoring detail to account for the new material, and again stressed the importance of providing feedback via comments.

To motivate quality of reviews, the students were made aware that the 3-4 student reviews would count towards $50 \%$ of the IPR grade, with $50 \%$ from the instructor. In addition, students were each awarded 10 bonus points (equivalent to $0.5 \%$ of the course possible points) for a complete review. Only 5 bonus points were given if there were no comments provided.

The standard deviations were worked out for each of the 11 reports, and the average of those values came to $5.4 \%$ of the 120 point IPR. In other words, the standard deviation was $1 / 2$ of a letter grade, on average, between reviews of an IPR. From Figure 1a, it is also evident that the standard deviation was larger for reports that did not score as well (towards the right in the figure), indicating again that better reports are more easy to agree on.
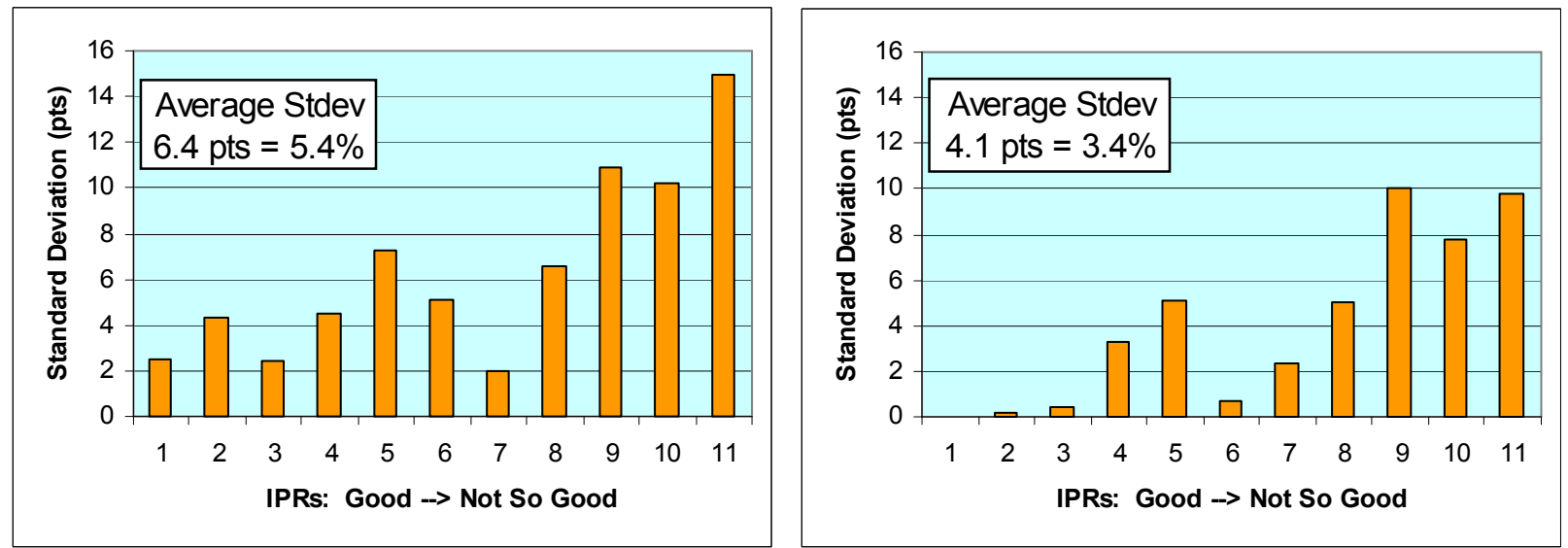

Figure 1: Standard deviations of (a) all student reviewer and instructor grades and (b) average student reviewer and instructor grades for eleven IPR 2 reports (USMA, Fall 2005, Heat Transfer)

Figure $1 \mathrm{~b}$ takes the standard deviation of the instructor grade and average student reviewer grade for each IPR. The average of these standard deviations is of course smaller, at only $3.4 \%$ of the 120 point IPR. For both measures of deviation, the student reviews matched up fairly well with that of the instructor, which was encouraging that they were putting the effort into the review process. These results were shown to the students in class. 
Course End Feedback

The same feedback system for Structural Analysis was used for Heat Transfer, and the same questions used for comparison of results. The results in Table 5 indicate that the addition of peer review into the course show a mixed trend in learning from peers and from oneself. It may be speculated that peer review was not utilized enough (only twice) to have a significant impact on these results.

Questions directed towards the peer review process are shown in Table 6, with comments grouped into positive, negative and neutral responses. Regarding the use of peer review for learning material, the response was overall positive but shows room for improvement. Some of the negative and impartial comments indicated a desire to have a fixed solution available to avoid errors in grading. The students felt uncomfortable grading design work that would not produce the same solution like a homework problem would have.

\begin{tabular}{|l|c|c|}
\hline Statement & $\begin{array}{c}\text { No Peer Review } \\
\text { Spring 2005 }\end{array}$ & $\begin{array}{c}\text { Peer Review } \\
\text { Fall 2005 }\end{array}$ \\
\hline $\begin{array}{l}\text { This instructor encouraged students to be } \\
\text { responsible for their own learning. }\end{array}$ & 4.61 & 4.64 \\
\hline $\begin{array}{l}\text { My fellow students contributed to my learning in } \\
\text { this course }\end{array}$ & 4.46 & 4.23 \\
\hline
\end{tabular}

Table 5 Survey Results, General Questions (USMA, Fall 2005, Heat Transfer)

\begin{tabular}{|c|c|c|c|}
\hline Question & $\begin{array}{l}\text { Positive } \\
\text { Response }\end{array}$ & Neutral & $\begin{array}{l}\text { Negative } \\
\text { Response }\end{array}$ \\
\hline $\begin{array}{l}\text { How did PEER REVIEW help you in learning } \\
\text { the material? }\end{array}$ & $60 \%$ & $11 \%$ & $29 \%$ \\
\hline $\begin{array}{l}\text { Will you use PEER review for future } \\
\text { assignments, even when not required? }\end{array}$ & $46 \%$ & $8 \%$ & $46 \%$ \\
\hline
\end{tabular}

Table 6 Survey Results, Peer Review Questions (USMA, Fall 2005, Heat Transfer)

There is an even distribution of feedback in the response for using peer review in the future. Many of the students indicated a reluctance to use peer review due to the cost in time, even though they agreed with the value in its purpose. It is apparent that the professional and ethical necessity for peer review needs to be made clearer during future implementation of the process, to outweigh the additional time expense. Specific comments are given in Appendix E for the question "How did peer review help you in learning the material?"

The next implementation of the peer review process will occur in the spring 2006 offering of Heat Transfer, which currently has 44 seniors enrolled. The biggest improvement will be an increased emphasis on the professional and ethical necessity of the review process.

\section{Fluid Mechanics Course at Stevens Institute of Technology}

The peer review process was introduced as a requirement of Fluid Mechanics (CE342), a junior level engineering course, at Stevens Institute of Technology during the fall of 2005 . Homework 
was assigned weekly and peer review was used frequently throughout the semester. At first the students were given two double blind peer reviews to complete. Since this was not received well, the remaining peer reviews were completed openly with the reviewer knowing whose work was being checked. The form used during the semester appears in Appendix B.

The peer review process was graded out of a total of 10 points and recorded as a homework grade. This provided incentive for the reviewer to take the peer review seriously and complete the task thoroughly. Unfortunately this incentive did not accomplish the goals set forth by the instructor. Some students took the review process seriously while others simply completed the required information at the top of the sheet and handed it in without ever looking at the assignment they were responsible for checking.

Conclusions as to the results and reactions of the peer review process cannot be made without first introducing some dynamics of this Fluid Mechanics class. Fluid Mechanics is a required course for most engineering students at Stevens, typically taken during the junior year. Two unique sections are offered, ME342 and CE342. The ME section is required for all Mechanical Engineering students while the CE section is required for all Civil and Environmental Engineering students. Students majoring in Chemical Engineering and Engineering Management may choose between the two. During the fall 2005 semester, 39 students were enrolled in CE342. The makeup of these students was as follows:

$\begin{array}{ll}\text { Civil Engineering } & 19 \\ \text { Environmental Engineering } & 2 \\ \text { Engineering Management } & 14 \\ \text { Chemical Engineering } & 2 \\ \text { Engineering Undecided } & 2\end{array}$

Many of these students were also part of the Cooperative Education (Co-op) program at Stevens which requires the students to work in their field of interest for three semesters between their sophomore and senior years. These students take five years to complete the bachelor's degree but have significant real life engineering experience when they graduate. It was these students who took a very positive attitude toward the peer review process and understood the importance of reviewing work performed by other engineers. The remaining students however, took some time to "buy into" the process and some never fully accepted the idea. To them, it was like having an additional assignment each week.

The peer review process was introduced during the first lesson by the instructor and outlined on the course information sheet. Students immediately began a lively discussion as to the process. Two themes which immerged were the identity of the two students, the reviewer and the student who completed the assignment and the request for the solutions prior to the completion of the peer review. The identity issue was addressed by having the first two peer reviews completed using randomly assigned numbers for each student instead of a name. This proved to be nothing more than a huge administrative effort and had no impact on the effort made to complete the assignment and the peer review. The anonymous submission actually provided the student with an unrealistic level of protection from their peers. They did not take the time to submit a well 
prepared and accurate assignment; no extra effort was made even though someone other than the teacher would review the work.

The policy was revised such that all subsequent peer reviews would be done openly. The idea of posting the solutions to the assignment prior to the completion of the peer review was not as easily addressed. The students were focused mainly on the solution to the problems and were not comfortable reviewing an assignment without the solution set available to them, as was witnessed in the USMA Heat Transfer course. The reality that in real life engineering, solutions are frequently not available did not seem realistic to the students. The Co-op students on the other hand came to the teacher's defense and tried to illustrate the importance of checking a peer's work without the benefit of solutions. One student even went as far as researching engineering failures which could have been prevented had the "reviewer" found the mistake prior to the design being constructed. They discussed the idea that most engineering designs are unique and thus no one solution exists. These facts and examples were not fully accepted by many of the students who continued requesting the solutions.

The policy to not provide solutions was retained, as peer review is ineffective if the solutions are available. Many of students are focused on the numerical solution and do not fully accept the idea of reviewing the total solution. Engineering problems on a whole involve assumptions, data from graphs and charts as well as conversions. The peer review process is designed to have the students check the methodology and underlying assumptions and not just the numerical solution. It was hoped that peer review would make this obvious to the students and they would see how minor differences in methodology may or may not affect the solution. However, the resistance continued throughout the semester as can be seen from the end of the semester assessment.

At Stevens Institute of Technology like West Point, students are asked to complete end of semester course assessments. The system is also web-based and has a series of institute wide questions as well as questions which are department and course specific. The CE342 assessment included two questions pertaining to the peer review, similar to those in the West Point courses.

\section{How did the peer review help you in learning the course material?}

\section{Will you consider using peer review for future assignments to help you better understand the course material?}

The response rate to the survey was $60.5 \%$. The responses are shown in Figure 2. The students' response to the questions needs to be chosen from those available within the assessment software. The scale of learning experiences was chosen as the best fit and students were instructed to correlate the "learning experience" with the "likelihood" that they would use the peer review process independently in the future. In other words, students were instructed that Great Learning indicated that they would definitely use peer review for future assignments while Little Learning meant that they would not. The results clearly indicate that students typically will not willingly review the work of their peers unless required to do so by the instructor 


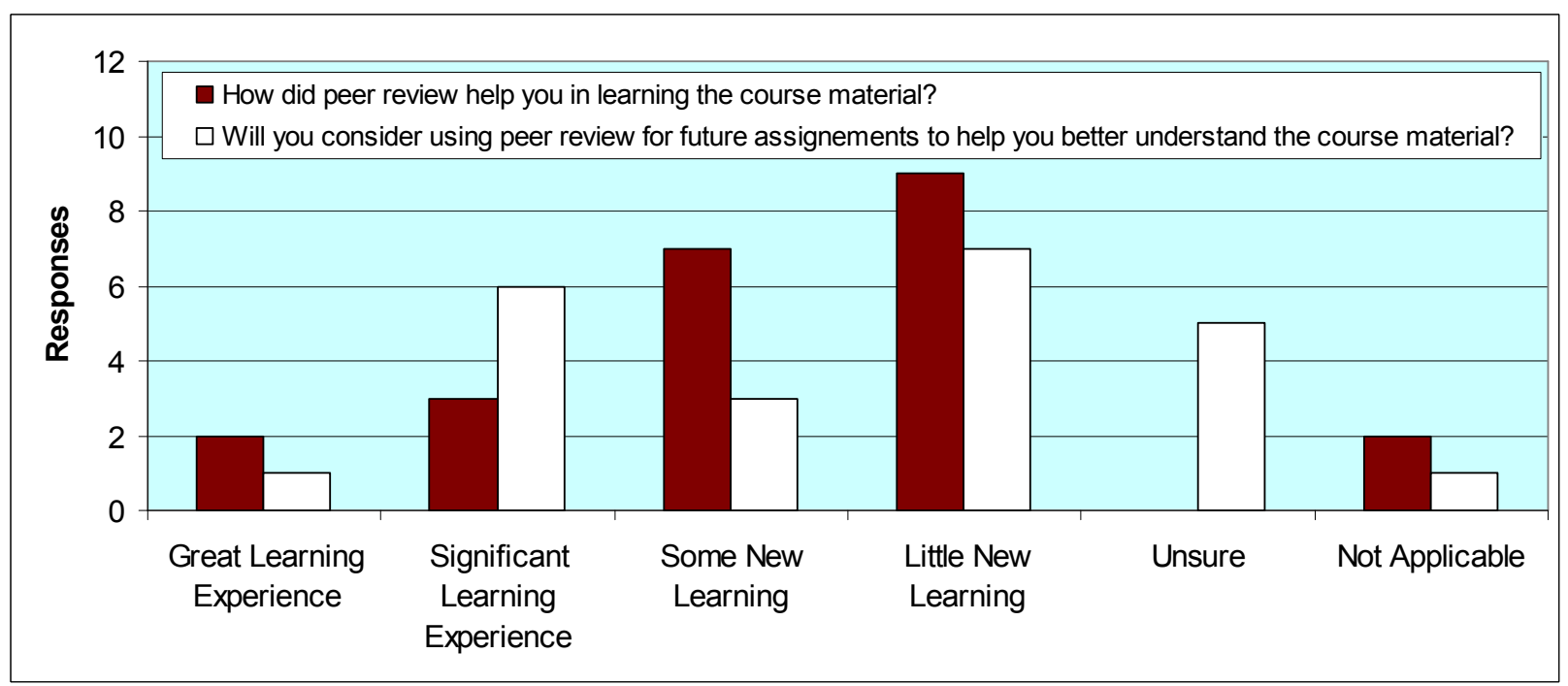

Figure 2 Student Survey Results (Stevens, Fall 2005, Fluid Mechanics)

Students were also asked to make suggestions which would make the peer review more valuable to students in the future. These comments further illustrate the diverse acceptance of the peer review process and the continued resistance to check work without referenced solutions. Comments from students pertaining to the peer review can be found in Appendix F:

The results of the assessment clearly indicate that the peer review process at Stevens Institute of Technology is a tool that needs some refining before it will be accepted by the students. The next implementation of the peer review will be in Water Resources Engineering, during the spring of 2006. This Civil Engineering course involves a great deal of open ended design problems. Requiring peer reviews of the homework should help illustrate that the methodology and sequence of the solution is as important as the solution. The students will hopefully see first hand how most engineering design problems do not have one single solution.

\section{Conclusions}

It has been shown that the professional practice of peer review can be successfully applied in an undergraduate academic environment, albeit with some initial resistance from the students. Not only does the process introduce a critical concept used in engineering practice, but it enhances learning from oneself and one's peers. There are some common threads found from results of the three approaches utilized at West Point and Stevens that are worthy of discussion.

The students needed to be made aware of and continuously reminded of the value of the process, or it would quickly become nothing more than a nuisance to them. Effective "marketing" is the key. While marketing may not be a term that we like to associate with educational methods, it does capture what is required. "Extensive research has shown that students learn best when they perceive a clear need to know the material being taught. ${ }^{[20]}$ Being able to tie what is done in the classroom to skills needed for future courses, or better yet their future careers after college is a huge motivator for students. ${ }^{[21]}$ If students believe that they really do need to know how to do something or learn a body of material, they will tend to work harder at learning and doing their 
best. ${ }^{[7,22]}$ The authors' use of the term "marketing" expresses the need to persuade and motivate students to engage fully in this or any educational methodology.

Stressing the importance of peer review within the engineering profession by introducing students to the Professional Code of ethics will provide an increased level of commitment to the process. Many undergraduate students are introduced to the licensure process during their junior and senior years when they typically prepare to take the Fundamentals of Engineering Exam. It is at this time that the requirements of the profession and the codes of ethics should be introduced. The correlation between the checks and balances required of a professional engineer and the peer review process illustrates the fact that this is an essential part of the engineering profession.

The process of peer review was largely unfamiliar to the students, and so it needed to be presented with enough instruction and organization such that the mechanics would not interfere with the objectives. The instructors should not have expected students to completely understand the process and what was expected of them. The authors found they had to teach them how to successfully complete the peer review. Proper instruction to prepare students to learn is certainly not a new idea, yet seemed to be overlooked when dealing with the basic concepts of the peer review initially. There is educational literature which recognizes "bringing students to the point of readiness as a significant part of teaching". ${ }^{[23]}$ The authors completely agree with this sentiment. Educational skills need to be developed by a structured process, which includes new educational methodologies. ${ }^{[24]}$

There must be a willingness to assess and adjust the mechanics of the methodology as needed. Involving other faculty and especially students in the assessment and revision of the educational system pays big dividends, and will encourage students to appreciate the lifelong benefits of peer review.

1. Hooker, R., editor, The Code of Hammurabi. 1996, Washinton State University.

2. Murray, M.H., Building Networks through Peer Interaction. Journal of Professional Issues in Engineering Education and Practice, 1999. 125(4): p. 159-162.

3. Gandolfo, A., Motivating Students for Life-long Leaning: Developing Metacognition. Journal of Professional Issues in Engineering Education and Practice, 2001. 127(3): p. 93-97.

4. Johnson, R.T. and D.W. Johnson, eds. An Overview of Cooperative Learning. Creativity and Collaborative Learning, ed. J. Thousand, A. Villa, and A. Nevin. 1994, Brookes Press: Baltimore.

5. $\quad$ Felder, R.M., A Longitudinal Study of Engineering Student Performance and Retention. IV. Instructional Methods and Student Responses to Them. Journal of Engineering Education, 1995. 84(4): p. 361-367.

6. Matthews, R.S., et al., Building Bridges Between Cooperative And Collaborative Learning. Cooperative Learning and College Teaching Newsletter, 1996. 6(1): p. 2-5.

7. Wankat, P.C. and F.S. Oreovicz, Teaching Engineering. 1993, New York: McGraw-Hill, Inc. 370.

8. $\quad$ Ngeow, K., Enhancing Student Thinking through Collaborative Learning. ERIC Digest, 1998.

9. Lowman, J., Mastering the Techniques of Teaching. 2nd ed. 1995, San Francisco: Jossey-Bass. 344.

10. Cooper, J. and P. Robinson, Small-group Instruction in Science, Mathematics, Engineering and Technology (SMET) Disciplines: A Status Report and an Agenda for the Future. Journal of College Science Teaching, 1998.

11. Cooper, J.L., P. Robinson, and M. McKinney, Cooperative Learning in the Classroom. 2002, Network for Cooperative Learning in Higher Education. 
12. Felder, R.M., G.N. Felder, and E.J. Dietz, A Longitudinal Study of Engineering Student Performance and Retention. V. Comparisons with Traditionally-Taught Students. Journal of Engineering Education, 1998. 87(4): p. 469-480.

13. Johnson, D.W., R.T. Johnson, and M.B. Stanne, Cooperative Learning Methods: A Meta-Analysis. 2000, University of Minnesota: Minneapolis, MN. p. 1-29.

14. Felder, R.M. and R. Brent, Cooperative Learning in Technical Courses: Procedures, Pitfalls, and Payoffs. 1994, ERIC Document Reproduction Service, ED 377038.

15. Light, R.J., The Harvard Assessment Seminars: Second Report. 1992, Harvard Graduate School of Education: Cambridge, MA.

16. Glaser, W., The Quality School--Managing Students Without Coercion. 1990, New York: Harper Perennial.

17. Hamilton, S.R. Peer Review: Modeling Civil Engineering Practice, Another Way To Improve Learning. in ASEE Conference \& Exposition. 2005. Portland, OR: ASEE.

18. Austin, A.W., What Matters in College: Four Critial Years, Revisitied. 1993, San Francisco: Jossey-Bass.

19. Gandolfo, A., E-mail: PEER REVIEW POLICY v 2.doc, S.R. Hamilton, Editor. 2004: West Point, NY.

20. Felder, R.M., Changing Times and Paradigms. Chemical Engineering Education, 2004. 38(1): p. $32-33$.

21. Felder, R.M. and R. Brent, FAQs IV Dealing with Student background Deficiencies and Low Student Motivation. Chemical Engineering Education, 2001. 35(4): p. 266-267.

22. McKeachie, W.J., Teaching Tips: Strategies, Research, and Theory for College and University Teachers. 10th ed. 1999, Boston: Houghton Mifflin.

23. Leamnson, R., Thinking About Teaching and Learning. 1999, Sterling, Virginia: Stylus Publishing, LLC. 169.

24. McGourty, J., P. Dominick, and R.R. Reilly. Incorporating Student Peer Review and Feedback into the Assessment Process. in FIE Conference. 1998: IEEE. 
Appendix A: Design review policy, 2005 "final" version--Structural Analysis and Advanced Structural Analysis

\section{DESIGN REVIEW POLICY}

It is important in Civil Engineering to take the steps necessary to get the correct answer. Remember Hammurabi's Law? In the "real world" practice plans, drawings and specifications are reviewed and a responsible licensed PE is required to stamp them. In academia publications and research are also subjected to peer review prior to publication.

Thus, this semester all your problem sets will be reviewed by two of your classmates prior to their being turned in. This approach to having your work reviewed is called DESIGN REVIEW, and this idea, if not our process, may be familiar to you from other courses. The objective of DESIGN REVIEW in our course is two fold. First and primarily, it is to help increase your learning and knowledge of structural analysis by having you review work of your classmates, as well as requiring you to have to explain your own work to them. It will also give you a good idea of your relative strengths and weaknesses in the various topics we will cover this semester. It is expected that when disagreements in answers or approach are encountered you will take the time to discuss them and determine if an error or misunderstanding of a concept does exit, and if so how to correct it. In order for this to happen you must prepare your work in a timely manner in order to allow it to be adequately reviewed. It must also be clearly presented to allow your reviewers, your classmates, to easily follow it. The second reason for design review is to also emphasize that it is important in Civil Engineering to take the steps necessary to get the correct answer!

As an incentive to make sure that you treat this part of the assignment as importantly as the calculations and other work you do, DESIGN REVIEW will count $10 \%$ of the possible grade on each assignment and provide an opportunity for you to earn additional points as well. Each of you must provide two design reviews of each assignment and have your work reviewed by two different people. You are encouraged use many different reviewers throughout the course, and may not use the same reviewers for consecutive assignments. You will notice that each assignment has two deadlines attached to it. The first is the time you are required to have the work and design review completed. The second time, typically 1 day later, is the time the work is to be turned in for grading. This will allow you to go over the design review comments, make changes to your work, or decide that no changes to your work are necessary.

There is a DESIGN REVIEW Sheet provided with each assignment, a copy of which is attached here. This sheet will have a space for each reviewer to annotate the time they reviewed the work and the results of their review. So what are you looking for? Certainly you are looking to see if the "final answer" is correct, but more than that you are checking to see if the work follows and applies the appropriate theory and methodology, is it clearly presented, does the work makes sense, is it complete, and finally do the answers make sense (this is hugely important for you as a budding engineer!).

What is not helpful in this process? Providing a bogus DESIGN REVIEW; examples of bogus DESIGN REVIEW include, but are not limited to: 
- Checking off on work you have not done yourself.

- Checking off as correct work that is wrong, yet you got correct.

- Checking off on work with very basic and obvious deficiencies.

In the unlikely event that a bogus DESIGN REVIEW takes place, the reviewer will be penalized. You will not be penalized for a bogus DESIGN REVIEW if your design review group all comes up with a wrong answer, assuming you all think it is correct and that is a logical assumption based on the work shown. Similarly, you will not be penalized if after review you all think the other's work is wrong and no one can convince the other members to change their answers. This rare case must be fully explained by all parties, however, with reasons why you are convinced your answer is correct. Remember, ideally you will all only provide genuine and accurate DESIGN REVIEW, so there should be no penalties. Especially good design reviews, those that are thorough, clearly provide meaningful comments that will help the engineer, offer insight, and demonstrate the reviewer's care and understanding will be given bonus points. In addition, at the end of the semester, we will have awards for the top Design Reviewers. 


\section{DESIGN REVIEW 1}

Date/Time Review Completed:

Does the work follow and apply the appropriate theory and methodology? YES NO $\square$ Explain below

Is the work complete and easy to follow?

YES

YES

NO

Explain below

Do the answers make sense?

REVIEWER COMMENTS:

REVIEWED BY:

Initials:

\section{DESIGN REVIEW 2}

Date/Time Review Completed:

Does the work follow and apply the appropriate theory and methodology? YES

NO

Explain below

Is the work complete and easy to follow?

YES

NO

Explain below

Do the answers make sense? $\quad$ YES $\square$ NO $\square$ Explain below

REVIEWER COMMENTS:

REVIEWED BY:

Initials:

ENGINEER'S COMMENTS: 
Appendix B: Peer review sheet for Fluid Mechanics (Stevens, Fall 2005)

\section{Peer Review Form CE342 Fluid Mechanics}

Reviewed Engineer:

Problem Set:

Original Work done by student number:

Date Review was completed:

Date Review is due:

Does the work follow and apply the appropriate theory and methodology?

$\circ$ Yes

○ No

- Explain:

Is the work complete and easy to follow?

$\circ$ Yes

- No

- Explain:

Do the answers make sense?
○ Yes
- No
- Explain:

Is the work presented in a professional manner?
- Yes
- No
- Explain: 
Appendix C: Student Comments, Structural Analysis

"The design reviews allowed me to not only help my classmates but also made me go back and review the material prior to reviewing my classmates."

"Sometimes it feels like my problem sets were completely wrong, but when I took them to a fellow civil cadet, I would see that I only miscalculated a single equation. This helped me gain confidence in my abilities. Rather than giving up, the design review gave me the motivation to continue because I knew I could get help."

"Concepts I thought I understood, but did not, were corrected."

"The Design Review often helped us learn the course material because if our methods or answers were off, our classmates could correct them and help us to better learn the course material." 
Appendix D: Student Comments Advanced Structural Analysis:

"It helped by making sure we turned in quality products. Peers also have a way of explaining why a particular step is needed or important that sometimes a teacher can't convey."

"Peer Reviews helped because it would make me go back and double check my work because I didn't want to be the guy that had the wrong answers."

"Since [the previous course where I first used peer review] I have definitely seen the benefit of checking ones work with others. It made a significant difference in the quality and accuracy of my work." 
Appendix E Student Comments, Heat Transfer

Specific comments are given as follows for the question "How did peer review help you in learning the material?":

"It did help, though I would not admit it to your face."

"I was able to see some of the errors that other groups made and often times, our group made similar errors."

"Not at all. Often peers made mistakes in giving feedback."

"I think peer review was very helpful in correcting the [IPRs]. I learned a lot by having to correct someone else's. It also gave a very professional aspect to the course."

"It gave me a chance to see what my classmates were submitting and motivated me to go above their level." 
Appendix F: Fluid Mechanics at Stevens Institute of Technology:

Comments from students requesting solutions prior to competing the peer review:

"The peer review was useless because we did not have the solutions. Therefore how can two people grade each other's work if they got different solutions?"

"The thing about peer reviews is that it's difficult to grade someone else's work when you are unsure of the correct answer yourself. For this reason, I'm not sure served the purpose it was supposed to."

"I did not have the answers in front of me.... Even though I knew what I was doing, I did not think it was fair that someone had the right answer. I might have made a small mistake and [it] gets marked wrong."

"Students should at least know the final answer for peer review and homework, so we know if we're doing it right and if not, we can fix that."

"Having the solutions because you didn't know if the way you were grading it was right so you could have made the same mistakes twice."

Comments from students who found the peer review to be an effective learning tool:

"The peer review should be used more often."

"I think it's a somewhat effective learning experience. The only issue is that if you do not understand the material when you do the homework, your not going to understand when you look some else's homework over."

"The peer review is an interesting concept, in that it is practical for us as engineers to be able to check over the work of our peers."

"They should be conducted more often, and students should be shown how to correct an assignment correctly, or in a manor that is practiced in the real world." 